\title{
PROPOSTA DE METODOLOGIA PARA TESTES \\ QUALITATIVOS DE MAPAS 3D
}

\author{
Proposing of qualitative testing methodology for 3D Maps \\ MARCIO AUGUSTO REOLON SCHMIDT \\ LUCIENE STAMATO DELAZARI \\ Universidade Federal do Paraná - UFPR \\ Setor de Ciências da Terra - SCT - Depto. de Geomática \\ Curso de Pós-graduação em Ciências Geodésicas \\ Caixa Postal 19001 - CEP: 81531-990. Curitiba-PR \\ marcio.schmidt@gmail.com; luciene@ufpr.br
}

\begin{abstract}
RESUMO
O uso de representações cartográficas tridimensionais para visualização agrega os últimos avanços tecnológicos para a manipulação e armazenamento de dados espaciais com a capacidade de transmitir informações através de mapas. No entanto, o conhecimento cartográfico necessário para a construção destas representações não acompanhou a evolução tecnológica. Como consequência não existem princípios gerais de projeto cartográfico para a criação de mapas 3D. Uma tarefa comum nessa área é a navegação virtual, que pode ser definida como o processo pelo qual uma pessoa determina sua posição em relação a outros elementos da paisagem e utiliza este conhecimento para chegar a outros locais. Entretanto, a determinação da orientação relativa não é uma tarefa trivial em ambientes virtuais. Alguns auxílios à navegação nesses ambientes foram propostos na literatura, geralmente baseados em técnicas de orientação (chamadas metáforas) utilizadas por usuários para navegar em ambientes reais. Este artigo busca avaliar a eficiência de algumas destas metáforas no desenvolvimento da capacidade de orientação e no cumprimento da tarefa geográfica de navegação. Para isso, foi desenvolvida uma metodologia de testes que associa os métodos qualitativos de registro do raciocínio do usuário (método think aloud) (Elzzaker, 2004), e a avaliação por questionários. O resultado é um procedimento de baixo custo e eficaz na identificação dos elementos de representação utilizados como referência.
\end{abstract}

Palavras-chave: Mapas 3D; testes em cartografia; navegação 3D. 


\section{ABSTRACT}

The use of cartographic representations in 3D views combines the advantages of technological computers for the handling and storage of spatial data. However, the cartographic knowledge needed to build these representations did not follow the technological development. As a consequence there are not general principles of map design for 3D maps. A common use task with 3D maps is the virtual navigation, which can be defined as the process whereby a person determines its position relative to other elements of the landscape and uses this knowledge to bearing him/herself to other locations. However, determination of relative orientation is not a trivial task in virtual environments. For this, some navigation aids are proposed in the literature, usually based on analogies of electronic tools used to navigate in real environments. This paper evaluates the influence of some of these metaphors in the guidance ability to comply with the geographic task navigation. For this, we developed a testing methodology that combines qualitative think-aloud method and evaluation by questionnaires. The result is an effective procedure to identify the elements of representation used as reference.

Keywords: 3D Maps; cartography tests; 3D navigation.

\section{INTRODUÇÃO}

Este artigo apresenta os resultados da pesquisa para determinar a adequação das metáforas de navegação na capacidade dos usuários navegarem em ambientes virtuais. Por metáfora entende-se uma analogia entre ferramentas de navegação em meio digital e a navegação em meio real. Para cumprir este objetivo foi desenvolvida uma metodologia de baixo custo para testes qualitativos em cartografia que foram aplicados a mapas 3D.

A aplicação e o dinamismo de mapas 3D são potencializados pela capacidade de manipulação e armazenamento de dados da informática, pois permitem incorporar conceitos como interatividade e mudança do ponto de vista que são fundamentais para a criação do senso de realidade virtual. Entretanto, a evolução tecnológica deu-se em um ritmo maior que o desenvolvimento dos conceitos necessários para construção de representações eficientes e, como conseqüência, não existem princípios gerais de projeto cartográfico para criação de mapas 3D como existem para o mapeamento temático. No entanto, essa falta de conhecimento em como estabelecer a linguagem cartográfica em representações tridimensionais abre um amplo campo para pesquisa. Alguns pontos específicos da representação 3D vêm sendo discutidos de maneira fragmentada na literatura por diversos autores ao longo dos últimos anos. Dentre esses aspectos, a orientação e a navegação em modelos 3D são objeto do presente trabalho que foi tratado primeiramente por Vinson (1999), Darken e Paterson (2001), Haeberling (2002), seguido de Tory et al (2004), Harrower e Shessley (2005), Haeberling et al (2008) e Fosse (2008), entre outros. Estes estudos avaliaram a capacidade de orientação de diferentes tipos de usuários com utilização de diversas metáforas de orientação nos 
modelos e nas interfaces dos mapas. Entretanto poucos buscaram entender como os usuários navegam e desenvolveram estudos comparativos sobre qual metáfora possibilita melhora na navegação. Para cumprir este objetivo, esta pesquisa desenvolveu uma metodologia de testes de baixo custo que associa diferentes tipos de testes qualitativos e quantitativos e será apresentada na sessão 3.

\section{COGNIÇÃO E NAVEGAÇÃO}

A navegação é definida, por Darken e Peterson (2001), como o processo que agrega orientação e movimento pelo qual as pessoas determinam sua posição e a posição relativa de outros elementos da paisagem, como forma de chegar a outros locais a partir de sua posição inicial. Segundo Burigat e Chittaro (2007), a navegação é uma tarefa que agrega o sentido de orientação e movimento. Segundo estes autores, o sentido de orientação é um elemento cognitivo da navegação que não envolve qualquer tipo de movimento, mas apenas decisões táticas e estratégicas que orientam o movimento guiado (Darken e Peterson, 2001). Estes autores salientam ainda que a essência do sentido de orientação é o desenvolvimento e uso de mapas cognitivos, ou mapas mentais.

Para navegar com sucesso no mundo real, as pessoas devem planejar seus movimentos utilizando o conhecimento armazenado nesses mapas mentais. No entanto, em ambientes virtuais a habilidade de localização e navegação normalmente se desenvolve muito lentamente, depois de longos períodos de navegação ou de estudo em representações, e os usuários nem sempre estão dispostos a investir este tempo (Vinson, 1999). Essa é uma razão adicional para que a criação de ferramentas de navegação envolva aspectos cognitivos, ou seja, para que o planejamento dos movimentos e a aquisição de conhecimento sobre o espaço sejam realizadas de maneira mais eficiente e acurada. De acordo com Darken e Peterson (2001), para a criação dos mapas cognitivos, os usuários recorrem a três tipos distintos de conhecimento espacial: conhecimento dos pontos de referência, conhecimento de rotas e conhecimento do terreno.

O conhecimento dos pontos de referência é a forma mais básica de conhecimento do ambiente. Um ponto de referência pode ser uma feição discreta que atua como ponto de ancoragem a partir do qual os usuários organizam outras informações espaciais em uma representação. A determinação destes pontos permite ao usuário avaliar o progresso ao longo de uma rota ou fornecer-lhe um rumo global. Um exemplo é o viajante que toma uma elevação ou pedra bastante significativa na região devido a sua altura ou características físicas, e estabelece sua posição em relação a ela. Ao se deslocar, o indivíduo utiliza sua posição em relação a essa pedra ou elevação para determinar a direção do seu deslocamento. O conhecimento de diversos pontos de referência organizados no mapa mental pode levar a um nível superior de conhecimento espacial, o conhecimento de rota.

O conhecimento de rota torna possível conectar diversos pontos de referência em uma sequência lógica no mapa mental do usuário e permite criar diferentes 
caminhos no ambiente. Desenvolvendo este conhecimento, a quantidade de informações sobre as relações entre as feições da rota aumenta. Além da seqüência, o conhecimento adquirido permite a estimativa de distâncias relativas. Neste nível de conhecimento os usuários reproduzem as características do percurso e a duração do mesmo. O conhecimento de rota permite que um usuário viaje para destinos através de rotas conhecidas, mas não permite tomar rotas suplementares (Kraft, 2001) devido a inexistência de pontos de referência nelas. Por rotas suplementares entendem-se outras rotas que surjam a partir da rota conhecida pelo usuário, também nomeadas na literatura como rotas derivadas.

A terceira classe de conhecimento é o do terreno, que descreve as feições da região e permite que os usuários avaliem as relações espaciais de diferentes objetos da área e identifiquem rotas suplementares (Burigat e Chittaro, 2007). Trata-se de uma síntese de rotas e pontos de referência que representa o nível mais alto de conhecimento espacial de um ambiente e caracteriza uma representação semelhante a mapas, hierarquizada, constituída de conceitos generalizados ou logicamente selecionados do ambiente (Darken e Peterson, 2001). Isto sugere que representações 3D generalizadas podem contribuir mais para a formação do conhecimento do terreno do que representações altamente realísticas, por simular o modo como os usuários pensam (Vinson, 1999; Burigat e Chittaro, 2007).

No entanto, o conhecimento de terreno pode conter distorções do ambiente, como o usuário lembrar-se de uma casa vermelha quando a casa é verde, ou virar a esquerda num cruzamento quando deveria ser à direita. Estas distorções nos mapas cognitivos dos usuários podem levar a erros de navegação e deformar a compreensão do usuário a respeito dos dados representados (Vinson, 1999). Os problemas na navegação são mais graves em mapas 3D, pois a quantidade de detalhes usada como referência na navegação pode ser drasticamente reduzida em conseqüência da oclusão causada pela posição e tamanho dos símbolos ou as configurações da câmera, entre outros. Por isso, apreender e lembrar de mapas 3D pode ser muito difícil para o usuário devido ao grande volume de informação e pelo reduzido número de pontos de referência para orientação fazendo com que os usuários percam a "consciência” de localização e fiquem perdidos.

Pesquisas têm sido realizadas para desenvolver ferramentas computacionais de auxilio à navegação, que permitam ao usuário explorar e apreender o ambiente ao seu redor, no sentido de evitar a desorientação e simplificar a navegação. Autores como Vinson (1999), Darken e Paterson (2001), Tory et al (2004), Harrower e Shessley (2005), estudaram a navegação assistida como auxílio na tarefa de navegação, de modo a ampliar as capacidades do usuário para explorar e conhecer ambientes virtuais. Os auxílios à navegação propostos geralmente se baseiam em analogias eletrônicas das ferramentas utilizadas por usuários para navegar em ambientes virtuais desconhecidos e tem como objetivo superar os principais problemas da navegação em mapas 3D os quais são descritos a seguir. 


\subsection{Os problemas da navegação em mapas 3D} são:

Os problemas com a navegação em mapas 3D, segundo Harrower e Sheesley (2005),

a) Limitações da perspectiva oblíqua: toda vista perspectiva 3D, animada ou não, sofre limitações, pois, como a escala não é constante ao longo da cena, é muito difícil para os usuários estimarem tamanhos relativos, distâncias e direções. Assim muitas tarefas de uso de representações que são facilmente realizadas através de mapas tornam-se um desafio na vista perspectiva, como, por exemplo, definir qual caminho é mais curto, ou qual é o maior lote.

b) Excesso de informações: abstração e generalização são elementos essenciais no aprendizado por meio de gráficos e mapas, e requerem a seleção cuidadosa das informações mais importantes e as tornam visíveis. As razões para abstrair e generalizar são reduzir o nível de detalhes para representar a realidade no mapa e expor relacionamentos e padrões. A generalização cartográfica em modelos 3D para navegação pode ser vantajosa para permitir que os usuários organizem mentalmente o espaço e a estrutura da paisagem, mas ainda está em fase inicial de pesquisas.

c) Oclusão visual: quando se visualiza uma superfície em perspectiva, porções desta superfície podem estar oclusas devido ao ângulo de visada ou associado às elevações do relevo. A pesquisa de Tory et al. (2004) relacionada à navegação de pedestres em área urbana revelou que a simultaneidade das vistas de topo (2D) e perspectiva (3D) é significativamente mais eficiente do que visualizar cada uma delas separadamente para orientação;

d) Desorientação do usuário: a desorientação é o maior desafio cognitivo para os usuários de ambientes virtuais (Harrower e Sheesley, 2005). Neste tipo de ambiente, o problema maior não parece estar na navegação em si, mas na manutenção da orientação. A questão é definir qual abordagem é mais adequada para cada uso deste tipo de representação. Uma das estratégias para amenizar o problema é usar metáforas para orientar os usuários.

\subsection{Metáforas para orientação}

As metáforas podem ser integradas no mapa 3D diretamente na interface do mapa, ou apresentadas juntamente com o mapa 3D, no modelo. A apresentação de ferramentas de orientação no modelo evita a necessidade do usuário dividir a atenção entre o mapa e a interface e permite que este se concentre na tarefa de exploração dos dados. Dentro do contexto de projeto cartográfico, espera-se que a eficácia de cada metáfora seja maior na execução da tarefa para a qual o mapa será utilizado. Por exemplo, uma bússola é supostamente mais apropriada para tarefas que exigem conhecer direções, enquanto que um mapa pode ser mais adequado para tarefas que exigem uma compreensão de toda a paisagem ou fenômeno. A seguir são listadas algumas metáforas selecionadas na literatura científica:

a) Pontos cardeais na borda do modelo (Haeberling, 2003; Fosse, 2008);

b) Rosa dos ventos (Haeberling, 2003; Fosse, 2008); 
c) Flechas 2D E 3D (Burigat e Chittaro, 2007);

d) Radar (Burigat e Chittaro, 2007): Esta ferramenta simula uma tela de radar, com círculos concêntricos na posição do observador. Quanto maior a distancia ao centro do circulo, maior a distancia a partir da posição do usuário. A posição em relação ao topo da tela sugere a direção a partir da posição do observador;

e) Uso de mapas associados a marca itinerante (Fosse, 2008);

f) Grade de referência (Harrower e Sheesley, 2005): Esta é uma grade colocada no plano do modelo; entretanto a sua orientação e o espaçamento entre as linhas não é a mesma da grade de coordenadas do mapa;

g) Bússola no horizonte;

h) Jetstrip (esteira de jato) (Harrower e Sheesley, 2005): Semelhante ao efeito de um avião em altas atitudes, o caminho percorrido pelo usuário fica identificado no espaço do mapa por uma faixa clara. Observando esta faixa o usário pode percorrer o caminho de volta até o inicio.

i) Carta topográfica.

Para este trabalho foram selecionados o mapa impresso, usado como referência, e o mapa digital com marca itinerante, pois ao se avaliar suas características são claramente mais inteligíveis aos usuários que as demais.

\section{METODOLOGIA DE TESTE}

A metodologia de teste realizada nesta pesquisa é uma associação de diferentes técnicas de testes de usabilidade. O objetivo é determinar qual das metáforas selecionadas é mais eficiente na navegação realizada em ambientes virtuais não imersiva. Os testes foram realizados nos laboratórios do Programa de PósGraduação em Ciências Geodésicas da Universidade Federal do Paraná. PPCG/UFPR, no período de dezembro 2009 a janeiro de 2010. O teste teve por objetivo avaliar o uso de metáforas para navegação em ambiente 3D, bem como testar a metodologia de teste proposta. Nesta pesquisa os usuários foram estudantes do Programa de Pós-Graduação. Em pesquisa subsequentes será definido o grupo de usuários específicos para continuidade dos testes.

\subsection{Materiais}

\subsubsection{Estação de testes}

Os testes foram realizados utilizando uma estação de testes composta de um computador AMD Athlon 4000+ $2.1 \mathrm{GHz}$ com 1Gb de memória RAM e sistema operacional Windows XP, 2 webcams e um microfone para registro do comportamento e verbalização do usuário. Os programas selecionados foram o STOIK Capture para gravação dos vídeos das webcams, o AutoScreen 3.1 Free para datalogging e o KAT MP3 Recorder para gravação do áudio do microfone. Estes programas são de uso livre (freeware), disponibilizados gratuitamente na internet. As câmeras são duas: uma disposta sobre a tela do computador, apontada para o 
rosto do participante e outra à sua direita. Esta montagem permite registrar as ações do usuário na tela do computador, suas expressões faciais, seu comportamento e verbalização das ações (figura 1).

Figura 1 - Montagem da estação de testes. Fonte: os autores.
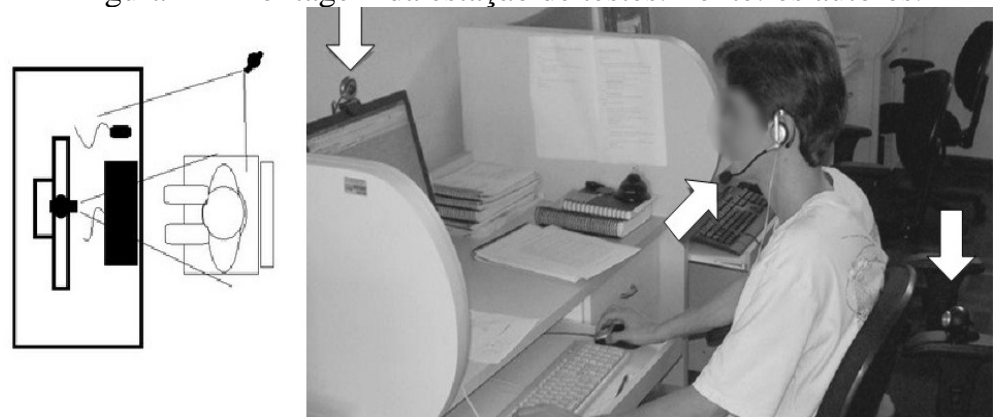

A chave de sincronização das gravações foi o registro do horário de início de cada sessão de testes. Os diferentes tempos foram colocados em um único referencial, de modo que fosse possível associar a expressão facial e a verbalização do usuário com suas ações num mesmo instante durante os testes. Pela simplicidade do registro das câmaras (datalogging) utilizado, esta sincronização foi realizada com um sinal sonoro, uma campainha acionada no começo do teste, gravada nas imagens das câmeras e no microfone. A sincronia das gravações foi realizada com o Windows Movie Maker, disponível no sistema Windows XP.

\subsubsection{Caracterização da área de estudo (modelos de teste)}

Para esta pesquisa foram utilizados os modelos híbridos criados por Fosse (2008) a partir de informações de uma restituição fotogramétrica na escala 1:2.000 da região de Macaé, RJ. Essa autora selecionou informações de relevo em pontos cotados e curvas de nível com eqüidistância de 5 metros, informações de hidrografia, sistema viário, vegetação e construções presentes na área. Para os testes, os modelos VRML foram adaptados aos objetivos desta pesquisa, através da inserção de uma esfera, árvores e edificações na representação. Esta alteração foi realizada principalmente com o programa 3DStudioMax, utilizado para manipular os objetos 3D e exportar para VRML. Para manipulação do mapa de referência e configuração das câmeras da VRML foram realizadas alterações no código de programação da VRML do modelo 3D, da página HTML e foi criado um javascript que faz a ligação destes dois últimos.

\subsection{Metodologia}

Os testes foram baseados na realização de uma única tarefa, a de encontrar uma feição específica no mapa 3D, uma bola vermelha. Os usuários foram divididos 
em 3 grupos, sendo que cada grupo utilizou uma metáfora de navegação. O primeiro grupo utilizou o mapa 3D sem qualquer ferramenta de auxílio à navegação; o segundo grupo consultou um mapa impresso por 15 minutos antes de iniciar a navegação; e o terceiro grupo utilizou o mapa digital exibido simultaneamente com o modelo 3D na tela do usuário. O encerramento da sessão de testes aconteceu por sucesso, desistência ou limite de tempo, este último fixado por testes preliminares em 20 minutos. Ao final, os participantes responderam a um questionário com perguntas referentes à caracterização de seu perfil acadêmico e profissional e às feições consideradas durante a navegação em mapas 3D.

\subsubsection{Métodos de coleta de dados}

Os métodos qualitativos, objeto de recentes pesquisas de uso de mapas, tratam de questões relacionadas a como os mapas funcionam na construção do conhecimento (Van Elzakker, 2004) e permitem avaliar o comportamento do usuário ao utilizar um sistema de navegação. Nesta pesquisa destacam-se os métodos qualitativos Think Aloud (Van Elzakker, 2004), e avaliação por questionários (Haeberling, 2002; Fosse, 2008) e uma ferramenta de registro de ações (datalogger).

a) Think aloud: este método de teste consiste na avaliação da verbalização das ações do usuário ao utilizar o sistema, o que proporciona ao avaliador a clareza na identificação de problemas de interpretação e entendimento de cada etapa do processo pelo usuário (Mendonça, 2009). Geralmente, este teste combina gravação de imagens e sons do participante enquanto este executa o teste. Para isto, o usuário deve narrar em voz alta o que está pensando à medida que o faz e, segundo Van Elzakker (2004), a vantagem deste método é que não há qualquer problema de memorização ou interpretação do raciocínio, pois eles são veiculados imediatamente. Entretanto este método consome muito tempo para análise e a correlação com outros dados sobre ações executadas durante os testes.

b) Uso de questionários: segundo Mendonça (2009), questionários são acessórios familiares, baratos e geralmente complementos aceitáveis para testes de usabilidade e avaliações de especialistas. Um grande número de questionários respondidos confere confiabilidade estatística ao teste, especialmente se comparados os resultados potencialmente tendenciosos e variáveis dados pelo pequeno número de participantes (Schneiderman, 1998). O principal uso de questionários é o de determinar o perfil do usuário, pois permitem descobrir algumas características não mensuradas por outro meio como, por exemplo, se usa óculos, grau de escolaridade, frequência e familiaridade com o uso de mapas, entre outros.

c) Datalogger: o registro de dados é uma ferramenta de teste, pois permite a análise das atividades do usuário através de gravações das suas ações de interação realizadas através do mouse ou teclado. $\mathrm{O}$ uso desta ferramenta neste trabalho permitiu a avaliação das ações do usuário, ações paralelas à tarefa principal e 
sincronização dos dados obtidos a partir dos demais métodos citados na determinação de pontos críticos da navegação.

\subsubsection{Teste preliminar e aplicação dos testes}

O tempo total do teste foi estimado em 20 minutos, a partir de sua aplicação preliminar a 3 alunos de graduação do curso de Engenharia Cartográfica e do Programa de Pós-Graduação em Ciências Geodésicas da Universidade Federal do Paraná. Os participantes utilizaram os mapas 3D em uma situação semelhante ao teste principal com a diferença na feição a ser encontrada, neste caso um farol. Após a fase de teste com o grupo experimental, os testes principais foram aplicados aos 8 participantes restantes. Para cada participante a tarefa de navegação foi inicialmente explicada com a seguinte instrução: "Siga para o norte. Em determinado ponto, entre as casas e próximo a uma igreja, existe uma bola vermelha. Encontre-a e volte ao ponto inicial". Esta tarefa, apesar de simples, compreende três importantes momentos no contexto da pesquisa:

1 - Inicialmente o usuário deve se localizar na representação. Isto é realizado com o estabelecimento de ao menos um ponto de referência na representação, ou no mapa auxiliar usado como metáfora;

2 - O participante deve estabelecer uma série de pontos de referência durante o seu deslocamento e concatená-los em uma rota no seu mapa mental. Os relatos dos pontos de referência poderão ser coletados à medida que o participante interage com o mapa 3D. Entretanto, a utilização das metáforas de navegação deve diminuir o número de pontos de referências;

3 - A terceira análise é a consistência das rotas através das metáforas. Uma metáfora é considerada mais ou menos eficiente pela quantidade de trechos do caminho de ida que o usuário conseguiu retomar no caminho de volta até o ponto de partida. Para isso, no questionário foi solicitado que os usuários que adotaram outro caminho na volta, justificassem esta decisão. Esta análise considera que as metáforas utilizadas substituem alguns dos pontos de referência e rotas. Desta forma pode-se entender que a tarefa cognitiva de criar as rotas no mapa mental passa a ter um caráter mais geral, externo ao usuário, através de processos mentais que vários usuários compartilham de forma semelhante para atingir o mesmo objetivo.

\subsubsection{Critérios de análise}

Todas as informações coletadas durante os testes foram analisadas de acordo com os seguintes critérios:

Critério 1: Seleção dos participantes aptos ao teste

Dificuldades com os controles de navegação podem atrapalhar a interação com o modelo e prejudicar o cumprimento da tarefa de teste. Este critério foi utilizado para excluir participantes que notadamente não conseguiram interagir com modelo de maneira aceitável para o cumprimento da tarefa.

Critério 2: Característica dos objetos usados como referência. 
As gravações em vídeo, áudio e o datalloger foram relacionados em um mesmo referencial de tempo, através do qual foi possível marcar os momentos de introspecção, ou seja, de silêncio do usuário, com as imagens da tela e as suas reações. Este critério permite a coleta de indícios de quais feições são tomadas como pontos de referência e a freqüência de utilização das metáforas de orientação nas gravações.

Critério 3: Descrições dos caminhos na memória de curta duração.

As descrições dos participantes no questionário, realizada logo após o final do teste, foram utilizadas para avaliar quais as feições ficam presentes na memória de curta duração do participante, ou seja, aquilo que se recorda logo após o teste. As descrições indicam quais feições do modelo foram usadas como referência e a influência da utilização das metáforas na retenção de informações representadas.

\section{RESULTADOS E DISCUSSÕES}

O conjunto de testes foi formado por 3 participantes nos testes preliminares e 8 para os testes principais, escolhidos aleatoriamente no curso de Engenharia Cartográfica e no Programa de Pós Graduação em Ciências Geodésicas da Universidade Federal do Paraná. Além destes, 2 participantes do teste principal foram excluídos pelo critério de usabilidade do plugin VRML Cortona 6.

Isso nos levou a ter participante de mais de um grupo de modo que um membro do grupo 1 também é membro do grupo 2 ou grupo 3 . O número de participantes pode ser explicado pelo fato de que não foi encontrada nenhuma referência sobre o tamanho da amostra necessária para este tipo de investigação. Por essa razão foi adotado o critério de Nielsen (1988) sobre a usabilidade de interfaces computacionais, que afirma que mesmo um número pequeno de participantes é suficiente para apontar os aspectos mais críticos das interfaces. Apesar do objetivo desta pesquisa ser avaliar a metodologia de testes, e não a capacidade cognitiva dos usuários, os autores sugerem que os mesmos merecem ser aprofundados. A figura 2 apresenta a caracterização dos participantes.

Figura 2 - Caracterização dos grupos de teste. Fonte: os autores.

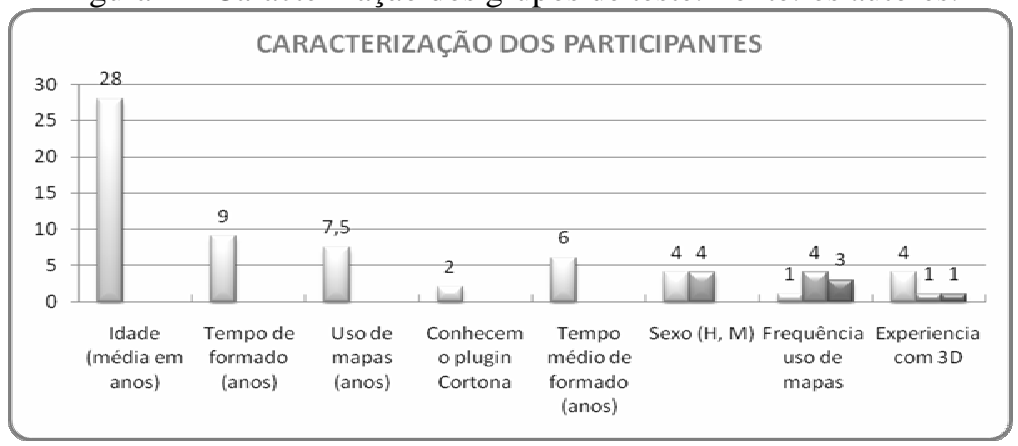

Bol. Ciênc. Geod., sec. Artigos, Curitiba, v. 16, nº 4, p.575-588, out-dez, 2010. 


\subsection{Resultados dos grupos de teste}

A maior parte dos participantes do grupo 1, 5 pessoas usando o mapa 3D, ignorou os pontos de referências (árvores e construções) presentes no entorno de sua posição inicial ao perceberem um bosque numa elevação. Aparentemente, esta feição serviu como referência global por ser visível a partir de vários pontos do modelo. As obras civis de maior destaque, como as igrejas e o farol, foram lembrados como referências locais. A simbologia das igrejas foi construída com as torres mais altas que as edificações em volta e seus telhados em tons de amarelo, cor incomum numa representação topográfica, o que ajudou na sua seleção como ponto de referência. Este grupo levou cerca de 30\% a mais de tempo em relação aos demais grupos (cerca de 17 minutos em média) para cumprir a tarefa de navegação e houve um maior número de registros de dúvidas nas gravações. Entretanto, este grupo foi capaz de representar o caminho percorrido nos questionários com maior riqueza de detalhes em relação aos demais grupos e, neste caso, a construção da simbologia foi fundamental para o sucesso da navegação

O grupo 2 (composto por 3 pessoas) utilizou o mapa impresso da área por 15 minutos antes de interagir com o mapa 3D. Entretanto, todos os participantes afirmaram estar satisfeitos com a leitura do mapa em menos tempo, o que posteriormente mostrou-se insuficiente em todos os casos. Neste grupo os participantes verbalizaram o uso de um polígono de vegetação rasteira como ponto de referência, que somente podia ser visto em um sentido (do sul para norte). Por isso, no caminho de volta, todos os participantes realizaram uma curva à direita quando deveriam seguir à esquerda. Nas verbalizações houve vários registros de surpresa ao não conseguirem localizar o polígono de vegetação. No mapa impresso este polígono é bem destacado por seu tom verde com alta luminosidade. Este grupo registrou maior número de ocorrências de uso das representações lineares como referências, em especial as estradas. Isto pode estar associado à representação ser semelhante entre o mapa impresso e o mapa 3D.

No grupo 3 (3 pessoas), que utilizou a metáfora do mapa digital com a marca itinerante, houve um menor número de registros de situações de dúvida sobre qual direção seguir e de localização. Entretanto, como percebido nos questionários, os participantes deste grupo não conseguiram lembrar, em detalhes, as rotas seguidas após concluir a tarefa. Este resultado é oposto ao do grupo 1 que não utilizou qualquer metáfora de navegação. Além disso, a verbalização das ações foi sensivelmente menor em relação aos demais. Isto sugere maior demanda cognitiva por parte do usuário quando usa e interpreta o mapa, mesmo que não haja dificuldade de mudar mentalmente seu ponto de vista entre uma representação e outra.

Um exemplo das descrições pictóricas do caminho pelos participantes, realizada nos questionários, é apresentada na figura 3. Neste caso especifico, o participante guardou somente algumas feições como pontos de referência, mas 
parece lembrar com maior precisão o caminho percorrido. Ressalta-se que os dois bosques que aparecem no desenho estão nos dois extremos do modelo, longe da posição da bola vermelha que consistia a solução da tarefa de navegação. Esta a compressão do espaço, o bosque ao norte desenhado próximo a vila, é um exemplo de distorção do mapa representativo da área na mente do usuário. Nesta figura, pode-se perceber que os pontos de referencia de mudança de rota não foram lembrados pelo participante. Outra distorção notada na figura é a posição do bosque desenhado à esquerda, pois o participante colocou seu caminho por entre as árvores onde, na verdade, passava um rio. O caminho passava a leste desta posição.

Figura 3: Representação do caminho conforme lembrado por um participante do experimento. Fonte: o autor, baseado no desenho de um participante.

CRUZAMENTO

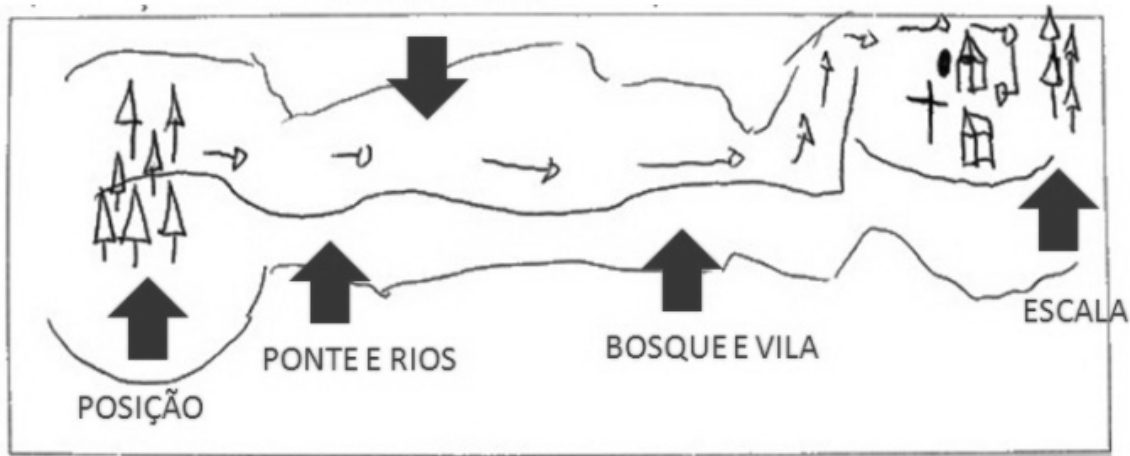

\section{DISCUSSÕES E CONCLUSÃO}

Esta pesquisa analisou alguns aspectos da orientação e navegação em ambientes virtuais, com enfoque nas ferramentas digitais de auxílio ao cumprimento desta tarefa. O objetivo neste artigo foi apresentar a metodologia de testes desenvolvida na pesquisa para coletar dados e avaliar a influência do uso de mapas impressos e digitais na navegação de um mapa topográfico 3D. A avaliação dessas metáforas e sua interação com os problemas de navegação num ambiente de testes contribuíram para o estabelecimento de uma metodologia para análises qualitativas de representações cartográficas tridimensionais.

Os testes indicaram que, no mapa 3D usado sem qualquer auxílio a navegação, a construção da simbologia se torna o ponto fundamental para o sucesso da navegação. Nesta abordagem, os testes evidenciaram que os pontos de referência globais tendem a ser mais importantes para a navegação do que os locais, ainda que a oclusão seja um problema. Neste caso, a situação se inverte, ou seja, os pontos de referência local são necessários a navegação. Estes resultados ainda apontam que a inclusão de pontos globais intervisíveis parece contribuir para que o usuário 
estabeleça uma base visual com a qual pode confrontar sua posição e orientação relativas.

Nos testes que envolveram a leitura do mapa impresso e nos testes realizados com o mapa digital com marca itinerante (grupos de teste 2 e 3, respectivamente), os os mapas favoreceram a navegação durante o cumprimento da tarefa. Porém, uma vez concluídas as tarefas, os usuários não conseguiram lembrar-se do caminho percorrido com o mesmo nível de detalhe do primeiro grupo. Isto destaca a necessidade de confirmação dos resultados dos testes para dirimir a aparente contradição em relação à afirmação de Darken e Peterson (2001) de que mapas digitais, reforçados por funcionalidades de auto-orientação e indicação da orientação do usuário, podem transmitir um amplo conhecimento sobre a região de estudo de modo mais eficiente. Pelos resultados obtidos, para chegar a tal nível de conhecimento de maneira consistente os usuários teriam que gastar tanto tempo analisando os mapas associados quanto o fariam somente com o mapa em papel

Os indícios coletados durantes os testes sugerem que a ausência de ferramentas de navegação na interface destes mapas 3D, exige um esforço maior do usuário para definir sua orientação relativa, e este esforço pode desenvolver seus mapas mentais de rotas com maior rapidez em relação aos outros métodos avaliados. Entretanto, isso não exclui a possibilidade de erros nestes mapas mentais; estes erros serão minimizados à medida que o tempo de interação com a representação aumente. Com esta pesquisa, de caráter inicial, não foi possível concluir que o uso de metáforas contribua ou não significativamente para melhorar de forma sensível o entendimento do fenômeno representado pelos participantes. Para esta resposta, mais testes e de maior profundidade precisariam ser desenvolvidos. Um dos pontos será aumentar o número de participantes, para obter maior confiabilidade estatística Recomenda-se que o projeto visual das ferramentas de navegação considere as mesmas soluções visuais adotadas na simbologia do mapa 3D como forma de atingir maior coerência de projeto e maior poder de comunicação dos mapas 3D.

\section{AGRADECIMENTOS:}

Ao CNPq pelo fomento através de bolsa de doutorado em 2008 e 2009, e pela concessão de Bolsa Produtividade em Pesquisa, processo 308892/2008-9; aos estudantes André Mendonça e Roberto Teixeira, e aos voluntários dos testes.

\section{REFERÊNCIAS BIBLIOGRÁFICAS}

BURIGAT,S. e CHITTARO, L. Navigation in 3D virtual environments: Effects of user experience and location-pointing navigation aids. Int. J. Human-Computer Studies 65 (2007) 945-958. doi:10.1016/j.ijhcs.2007.07.003, 2007.

DARKEN, R.P., \& PETERSON, B. Spatial Orientation, Wayfinding, and Representation. Handbook of Virtual Environment Technology. Stanney, K. Ed. 2001. 
FOSSE,J. M. Proposta de orientação geográfica para as representações cartográficas tridimensionais. Curitiba. 104 p. Tese de doutorado no Programa de PósGraduação em Ciências Geodésicas - Universidade Federal do Paraná. 2008.

HAEBERLING, C. 3D-map presentation: A systematic evaluation of important graphic aspects. Anais: ICA Mountain Cartography Workshop "Mount Hood”. International Cartographic Association. Disponível em http://www. mountaincartography.org/mt_hood/pdfs/haeberling2.pdf Acessado em: 21/07/09. 2002.

HAEBERLING, C., BÄR,H., HURNI,L. Proposed cartographic design principles for 3d maps: a contribution to an extended cartographic theory. Cartographica v. 43. i.3. pp.175-188. Doi:10.3138/carto.43.3.175. Acessado em: 12-08-09. Disponível em: http://web.ebscohost.com/ehost/ pdf?vid=1ehid=102esid= fdbb84ec-86ad-4835-945b-b4f1e54bd9a7\%40session mgr111. 2008.

HARROWER,M. e SHESSLEY,B. Moving beyond novelty: creating effective 3D fly-over maps. Anais: $22^{\text {th }}$ International Cartographic Conference Mapping Approaches into a Changing World. La Coruña, Spain, July 9-16, 2005. Disponivel em: http://www.geography.wisc.edu/ harrower/pdf/ICA2005 _paper. pdf. Acessado em: 24-07-09. 2005.

KRAFT, M.F. A neural optimal controller architecture for wayfinding behavior. Tese Computer Science and Psycology Department. Swarthmore College, USA. Disponível em: http://www.ifi.uzh.ch/ krafft/papers/2001/ wayfinding/html/node1.html. Acessado em: 10-08-09. 2001.

MENDONÇA, A. L. A. de. Avaliação de interfaces para mapas funcionais na web. Dissertação. Departamento de Geomática, Setor de Ciências da Terra, Universidade Federal do Paraná. PP 189. 2009.

SCHNEIDERMAN, B. Designing the user interface. Strategies for effective human-computer interaction. 3 ed. Addison Wesley Longman, Inc. 639p. 1998

TORY,M., MÖLLER, T., ATKINS, M.S., KIRKPATRICK, A.E. Combining 2D and 3D Views for orientation and relative position tasks. Anais: CHI 2004, V.6 N.1, Austria doi ACM:1-58113-702-8/04/0004. 2004.

VAN ELZAKKER,C. P. J.M. The use of maps in the exploration of geographic data. (Tese) Koninklijk Nederlands Aardrijkskundig Genootschap/ Faculteit Geowetenschappen, Universiteit Utrecht / International Institute for GeoInformation Science and Earth Observation. ISBN 90-6809-357-6. Labor Grafimedia b.v. - Utrecht, Holanda. Disponível em: http://www.itc.nl/ personal/elzakker Acessado em: 12-12-08. 2004.

VINSON, N.G. Design guidelines for landmarks to support navigation in virtual environments. Anais: CHI '99. Pittsburgh, USA. pp. 278-285. Disponível em: http://nparc.cisti-icist.nrc-cnrc.gc.ca/npsi/ctrl?action=rtdocean=9147118 earticle=12 Acessado em: 01-08-09. 1999.

(Recebido em junho de 2010. Aceito em outubro de 2010.) 